\title{
Exploring Differences in Demographic Variables and Alcohol Consumption amongst University Student-Athletes
}

\author{
Surujlal, J. \\ North-West University, Faculty of Economic Sciences and Information Technology \\ PO Box 1174, Vanderbijlpark, 1900, Republic of South Africa \\ Babs.Surujlal@nwu.ac.za /bsurujlal@gmail.com. \\ Keyser, E. \\ North-West University, Faculty of Human Sciences , PO Box 1174, \\ Vanderbijpark, 1900, Republic of South Africa \\ elsabe.keyser@nwu.ac.za.
}

\section{Doi:10.5901/mjss.2014.v5n23p820}

\begin{abstract}
University student-athletes have a high propensity to engage in risky behaviours, which result in negative health-related outcomes. Among the risky behaviours is alcohol consumption. This study was conducted to explore differences in gender, age and type of sport and alcohol consumption among university student-athletes. A quantitative research approach was used for the study. Coaches who were closely associated with student-athletes at three different universities administered a questionnaire to 400 athletes. Descriptive statistics using frequencies and percentages were used to report the demographic data. ANOVA were used to determine the differences between alcohol consumption, gender and type of sport. A negative statistically significant relationship between gender and years of study (-0.02) was found. A practically significant medium effect (0.44) was found between gender and type of sport. A practically significant relationship with a medium effect (0.31) was found between quantity consumed and frequency of consumption. The practice therefore, should be monitored closely, as it may have serious consequences on their athletic and academic careers.
\end{abstract}

Keywords: student-athletes, alcohol consumption, demographical variables, university, health, substance use.

\section{Introduction}

University student-athletes have a high propensity to engage in risky behaviours, which result in negative health-related outcomes (Ford, 2007). Among the risky behaviours practised by university student-athletes are substance use, unhealthy eating habits and unprotected sexual activity (Surujlal, Nolan \& Ubane, 2012). With regard to substance use, university student-athletes are likely to use substances, which are convenient and easily available to them. Among these are drugs, alcohol and tobacco. The current study focuses on alcohol consumption by university student-athletes.

It is surprising that while success in sport is highly dependent on student-athletes being able to maintain a high level of physical and mental health, university student-athletes continue to consume high quantities of alcohol (The Higher Education Center for Alcohol and Other Drug Abuse and Violence Prevention, 2008). Even more surprising is that university student-athletes have significantly higher rates of heavy drinking than non-athletes (Brenner \& Swanik, 2007). This is a growing concern for athletes as such behaviour impacts negatively on their athletic performance, academic success and social life (Hingson, Heeren, Winter \& Wechsler, 2005). The discrepancy between health-promoting and health-compromising behaviours of university student-athletes warrants attention due to the fact that university studentathletes are not only 'ambassadors' of their sports but also 'ambassadors' of the university. To an extent, the image of the university is portrayed through the behaviour of their student-athletes.

Studies (The Higher Education Center for Alcohol and Other Drug Abuse and Violence Prevention, 2008) have found that alcohol is the most used substance at college and university campuses with prevalence rates of 80-85 per cent. In particular, university student-athletes consume more alcohol, engage in more frequent heavy episodic drinking, and experience more negative alcohol-related consequences as compared with non-athletes (Brenner \& Swanik, 2007; Doumas, Turrisi \& Wright, 2006; Hingson et al., 2005, Nelson \& Wechsler, 2001).

University student-athletes are a unique group of the student population whose university experience is different 
from those of non-athletes (Hyatt, 2003). They are usually provided with support services beyond those that are offered to the general student population (Nelson \& Wechsler, 2001). They, in turn, are required to contribute in terms of their performance on the sport field. In addition to their sport participation, university student-athletes are also expected to fulfil their academic obligations in terms of participating in lessons, completing assignments and writing examinations. Because most student-athletes are accepted at university based on their athletic performance, their athletic participation and success overshadows their academic performance (Equihua, Jenness \& Stuekemann, 2012). They experience several stressors which include demanding schedules (Holden, 2014), stereotyping by the media, faculty and students (Lorenzen \& Lucas, 2003), time constraints (Singh \& Surujlal, 2006), physical and psychological stress and fatigue (Van Zyl, Surujlal \& Singh, 2009), and commitment to attend sport events (Olivares, 2005). In most instances, the public is oblivious to the hard work, early regimented workouts and the academic workloads that student-athletes experience instead they see only the glamour associated with athletic success (Equihua et al., 2012).

Student-athletes are often required to satisfy their coaches and fans through their sporting performance, their lecturers in terms of their academic performance and their parents in terms of both academic and sporting performance. In addition, they also have to satisfy the demands from sponsors and bursars. The pressure to deliver on the demands of the university, coaches, fans and family may influence student-athletes to turn to alcohol as a reprieve (Surujlal et al., 2012).

The stresses of a sporting career, however, may not be the only reason why student-athletes consume alcohol. Nelson and Wechsler (2001) suggest that sport clubs are, by nature, highly social organisations. The authors opine that as a result of this, athletes may be more likely to possess social characteristics, which predict alcohol consumption. In similar vein, Perkins (2002) suggests that peers, group norms and isolation from the general student body are likely to influence student-athletes to consume alcohol if that was the group norm. Another possible reason for alcohol consumption may arise from student-athletes transitioning from high school to university, which is accompanied by a new-found freedom from their homes and parental control (Watson, 2002). This freedom, accompanied by the elevated status they have at the university because of their sport achievements, peer pressure, balancing their sporting academic and social lives, and the desire to explore may result in them experimenting with substances such as drugs and alcohol. Challenges such as athletic failure (Cavenar \& Werman, 1981), physical injury (McDonald \& Hardy, 1990), and the termination of their athletic careers (Parham, 1993) may also result in them turning to alcohol for reprieve.

While much research has been conducted on university and college students in general, studies investigating alcohol consumption among university student-athletes in the South African context is sparse. Therefore, the purpose of this study is to explore the differences between gender, age and types of sport and alcohol consumption among university student-athletes.

\section{Methodology}

\subsection{Research approach}

A comprehensive literature review of alcohol consumption by university student was undertaken to provide the theoretical basis for defining the problem and research design, developing the empirical study and to contribute to a discussion of the findings. A descriptive survey design was used. This approach was adopted as this study seeks to quantify data and typically apply some form of statistical analysis. It makes it possible for conducting various statistical techniques (Creswell, 2014), allows for the collection of data from a large number of representative cases in a structured manner (Malhotra, 2007) and eliminating possible subjectivity of judgment.

\subsection{Sample}

Based on the convenient accessibility and proximity of student-athletes to the researchers a convenience sampling technique was used to recruit the study sample. In the context of this study, student-athletes are regarded as individuals who are skilled performers who participated competitively in inter-university sport under the auspices of the University Sport South Africa (USSA). Four hundred students at three university campuses were approached and requested to complete a questionnaire. Of these students $202(51 \%)$ returned completed questionnaires. For the sake of anonymity, universities are listed as A, B and C. 


\subsection{Instrument and procedures}

A four-section questionnaire was developed for the study. Section A sought demographic information of the respondents. In Section B, the drinking patterns of student-athletes were examined. Questions on both the quantity consumed per glass and frequency of consumption during a month provided data on the student athletes drinking patterns. Section $\mathrm{C}$ investigated the consequences of alcohol abuse, and Section D explored respondents' knowledge about alcohol. The overall internal consistency for Sections $B$ and $C$ was $a=0.741$, indicating that these sections satisfied the suggested benchmark of 0.7 (Nunnally \& Bernstein, 1994).

Coaches who were closely associated with student-athletes at the different universities were requested to administer the questionnaires to student-athletes during training sessions. The purpose of the study was explained to the participants both verbally as well as through a letter attached to the questionnaire. They were also informed that their participation was voluntary, their responses would be confidential and they would remain anonymous at all times.

\subsection{Data analyses}

Descriptive statistics using frequencies and percentages were used to report on the demographic data. Pearson correlation, which determines the extent to which values of variables are proportional in relationship to each other (Bernstein et al., 2007) was used to explore the relationship between demographic variables, frequency of alcohol consumption and quantity consumed. Furthermore, analysis of variance (ANOVA) were used to determine the differences between alcohol consumption by athletes and various biographical characteristics such as gender, age, years of study, type of sport and university.

\section{Results}

\subsection{Demographics}

Table 1 provides the demographic profile of the study sample. According to the table the majority of the participants $(n=136,67.3 \%)$ were aged $16-21$ years. More males $(n=114 ; 56.4 \%)$ than females $(n=88 ; 43.6 \%)$ participated in the study. The demographic information suggests that soccer attracted the highest participants $(n=66 ; 32.7 \%)$ followed by cricket $(n=36 ; 17.8 \%)$, softball $(n=35 ; 17.3 \%)$ and tennis $(n=20 ; 9.9 \%)$. The results showed that more of the participants $(n=95 ; 47 \%)$ were in their first year of study followed by those in the second year $(n=71 ; 35.1 \%)$.

Table 1: Demographic profile of study sample

\begin{tabular}{|c|c|c|c|}
\hline Item & Category & Frequency & Percentage \\
\hline \multirow[t]{3}{*}{ Age } & $16-21$ years & 136 & 67.3 \\
\hline & $22-27$ years & 56 & 27.7 \\
\hline & 28 years and older & 8 & 4.0 \\
\hline \multirow[t]{2}{*}{ Gender } & Male & 114 & 56.4 \\
\hline & Female & 88 & 43.6 \\
\hline \multirow[t]{11}{*}{ Classification of sport } & Soccer & 66 & 32.7 \\
\hline & Rugby & 16 & 7.9 \\
\hline & Cricket & 36 & 17.8 \\
\hline & Hockey & 11 & 5.4 \\
\hline & Tennis & 20 & 9.9 \\
\hline & Boxing & 3 & 1.5 \\
\hline & Gymnastics & 2 & 1.0 \\
\hline & Ice hockey & 6 & 3.0 \\
\hline & Squash & 4 & 2.0 \\
\hline & Softball & 35 & 17.3 \\
\hline & Athletics & 3 & 1.5 \\
\hline \multirow[t]{3}{*}{ University } & A & 93 & 46.0 \\
\hline & $B$ & 40 & 19.8 \\
\hline & C & 69 & 34.2 \\
\hline \multirow[t]{5}{*}{ Year of study } & $1^{\text {st }}$ year & 95 & 47.0 \\
\hline & $2^{\text {nd }}$ year & 71 & 35.1 \\
\hline & $3^{\text {rd }}$ year & 13 & 6.4 \\
\hline & Post graduate & 7 & 3.5 \\
\hline & Other & 16 & 0.08 \\
\hline
\end{tabular}




\subsection{Relationship between demographic variables and alcohol consumption}

The following guidelines, as suggested by Cohen (1988) were used to measure the strength of the relationship between the demographic variables and alcohol consumption.

Table 2: Strength of relationship between variables

\begin{tabular}{cc}
\hline Size of $r$ & Interpretation \\
\hline$\pm(0.5$ to 1.0$)$ & Large \\
$\pm(0.3$ to 0.49$)$ & Medium \\
$\pm(0.1$ to 0.29$)$ & Small \\
\hline
\end{tabular}

Source: Cohen (1988)

Table 3 reflects the strength of the correlations between the demographic variables, average frequency of alcohol consumption during one occasion during the past month and quantity consumed per glass. Pearson correlation was performed and none of the demographical control variables was correlated with average frequency of consumption during the month and quantity consumed per glass. The results indicate that a practically significant relationship with a medium effect was found between quantity consumed and frequency of consumption.

Table 3: Correlation analysis

\begin{tabular}{|c|c|c|c|c|c|c|c|c|}
\hline \multicolumn{2}{|c|}{ Variables } & \multirow{2}{*}{$\begin{array}{l}1 \\
1\end{array}$} & \multirow{2}{*}{$\frac{2}{-}$} & \multirow{2}{*}{$\frac{3}{-}$} & \multirow{2}{*}{$\frac{4}{-}$} & \multirow{2}{*}{$\frac{5}{-}$} & \multicolumn{2}{|c|}{6} \\
\hline 1. & Gender & & & & & & & \\
\hline 2. & Age & $-0.30^{* *}$ & 1 & - & - & - & & \\
\hline 3. & Years of study & -0.02 & 0.13 & 1 & - & - & & \\
\hline 4. & Type of Sport & $0.44^{* *}$ & -0.06 & -0.11 & 1 & - & & \\
\hline 5. & University & -0.05 & -0.00 & -0.09 & 0.02 & 1 & & \\
\hline 6. & Frequency of consumption during month & 0.01 & -0.01 & 0.11 & 0.02 & -0.02 & & \\
\hline 7. & Quantity consumed per glass & 0.03 & 0.12 & 0.10 & 0.01 & -0.03 & 0 & $.31^{* *}$ \\
\hline
\end{tabular}

\subsection{Alcohol consumption according to gender}

In Table 4 frequencies of type of alcohol consumed and Table 5 quantity consumed per glass by gender are presented. It is clear from Table 4 that male athletes wine consumption was 40.4 per cent per year, but beer consumption was 23.7 per cent per year. Female athletes' consumption of wine was eight per cent per day but 31.8 per cent at least once a month but less than once a week

Table 4: Frequencies of type of alcohol consumed and quantity consumed per glass by gender

\begin{tabular}{lcccc} 
& & Male & \multicolumn{2}{c}{ Female } \\
& $\mathbf{N}$ & Percentage & $\mathbf{N}$ & Percentage \\
\hline Wine & 10 & 8.8 & 7 & 8.0 \\
Every day & 7 & 6.1 & 10.2 & 28 \\
At least once a week but not every day & 24 & 21.1 & 28 & 31.8 \\
At least once a month but less than once a week & 27 & 23.7 & 24 & 27.3 \\
More than once a year but less than once a month & 46 & 40.4 & 20 & 22.7 \\
Once a year & & & & \\
Beer & 14 & 12.3 & 2 & 2.3 \\
Every day & 23 & 20.2 & 16 & 18.2 \\
At least once a week but not every day & 31 & 27.2 & 31 & 35.2 \\
At least once a month but less than once a week & 19 & 16.7 & 21 & 23.9 \\
More than once a year but less than once a month & 27 & 23.7 & 18 & 20.4 \\
Once a year & & & & \\
Spirits & 7 & 6.1 & 5 & 5.7 \\
Every day & 22 & 19.3 & 10 & 11.4 \\
At least once a month but less than once a week & 39 & 34.2 & 36 & 40.9 \\
At least once a week but not every day & 26 & 22.8 & 19.3 & 20 \\
More than once a year but less than once a month & 20 & 17.5 & 20 & 22.7 \\
Once a year & & & \\
\hline
\end{tabular}


Table 5: Quantity consumed per glass by gender

\begin{tabular}{|c|c|c|c|c|}
\hline & \multicolumn{2}{|r|}{ Male } & \multicolumn{2}{|c|}{ Female } \\
\hline & $\mathbf{N}$ & Percentage & $\mathbf{N}$ & Percentage \\
\hline \multicolumn{5}{|l|}{ Wine } \\
\hline Less than 1 glass & 46 & 40.4 & 21 & 23.9 \\
\hline 1 to 2 glasses & 22 & 19.3 & 16 & 18.2 \\
\hline 3 to 4 glasses & 23 & 20.2 & 34 & 38.6 \\
\hline 5 to 6 glasses & 10 & 8.8 & 8 & 9.1 \\
\hline $\begin{array}{l}6 \text { and more glasses } \\
\text { Beer }\end{array}$ & 13 & 11.4 & 9 & 10.2 \\
\hline Less than 1 glass & 33 & 28.9 & 17 & 19.3 \\
\hline 1 to 2 glasses & 16 & 14.0 & 10 & 11.4 \\
\hline 3 to 4 glasses & 15 & 13.2 & 25 & 28.4 \\
\hline 5 to 6 glasses & 12 & 10.5 & 23 & 26.1 \\
\hline $\begin{array}{l}6 \text { and more glasses } \\
\text { Spirits }\end{array}$ & 38 & 33.3 & 13 & 14.8 \\
\hline Less than 1 glass & 27 & 23.7 & 30 & 34.1 \\
\hline 1 to 2 glasses & 19 & 16.7 & 16 & 18.2 \\
\hline 3 to 4 glasses & 26 & 22.8 & 17 & 19.3 \\
\hline 5 to 6 glasses & 10 & 8.8 & 15 & 17.0 \\
\hline 6 and more glasses & 32 & 28.1 & 10 & 11.4 \\
\hline
\end{tabular}

The quantities per glass consumed are illustrated in Table 5. Male student athletes consumed less than one glass of wine per month, but 33.3 per cent consumed more than six glasses of beer per month. Most female athletes consumed more than three to four glasses of wine per month.

\subsection{Difference between alcohol consumptions, gender, age and type of sport}

ANOVA analysis indicates that there are no significant differences between gender and alcohol consumption, but as seen in Table 5 differences exist between scores of alcohol consumption (frequency of drinking beer, wine and spirits and the average number of these drinks consumed on any one occasion during the past month) by athletes and age.

Table 5: ANOVA - Differences in alcohol consumption, age and type of sport

\begin{tabular}{lccccc}
\hline Item & $\begin{array}{c}16-21 \\
\text { years }\end{array}$ & $\mathbf{2 2 - 2 7}$ years & $\begin{array}{c}\text { 28 years } \\
\text { and older }\end{array}$ & $\boldsymbol{p}$ & $\eta^{2}$ \\
\hline Frequency of consumption & 10.21 & 10.80 & 7.88 & $0.01^{*}$ & 0.06 \\
Quantity consumed per glass & 9.38 & 10.41 & 9.75 & 0.11 & 0.03 \\
\hline
\end{tabular}

$\eta 2>0.25=$ large effect

* Statistically significant difference: $p<0.05$

From the results presented in Table 5, it is evident that differences exist between athletes below the age of 28 years and those athletes that are older than 28 years. The ANOVA findings in Table 6 reveal that $p$ values are above 0.05 for all the different types of sport; hence, there are no significant differences between students-athletes quantity consumed per glass and type of sport.

Table 6: ANOVAS - Differences in alcohol consumption by athletes and type of sport levels

\begin{tabular}{|c|c|c|c|c|c|c|c|c|c|c|c|}
\hline Item & Soccer & Rugby & Cricket & Hockey & Tennis & Boxing & Squash & Athletics & Netball Other & & $\overline{\eta 2}$ \\
\hline Frequency of consumption & 9.83 & 10.75 & 11.23 & 10.43 & 10.00 & 3.00 & 14.00 & 12.00 & 10.4015 .0 & $0.01 *$ & $\overline{0.06}$ \\
\hline Quantity consumed & 9.38 & 9.86 & 9.85 & 9.14 & 12.8 & 8.00 & 12.00 & 8.00 & 15.0 & 0.11 & 0.03 \\
\hline
\end{tabular}

As evident in Table 6, differences were found in student-athletes frequency of consumption and substance use. A small 
significant difference effect exists between soccer player and other type of sport substance misused.

\section{Discussion}

Some significant relationships existed between students-athletes alcohol consumption and such variables as age, year of study and type of sport. The findings of the current study with regard to the age of the student-athletes corroborate those of Nelson and Wechsler (2003) who found that alcohol consumption differs significantly by age. Other studies (Leichliter, Meilman, Presley \& Cashin, 1998; Wechsler et al., 1997) also found that student-athletes consumed more alcohol and also engaged in more frequently heavy episodic drinking than non-athletes.

The higher alcohol consumption as well as frequency of consumption could be attributed to various factors. Upon entry into university life student-athletes may be more vulnerable to peer influence, which may result in them experimenting with, and consuming more alcohol more frequently (Surujlal et al., 2012). Toporek (2011) opines that student-athletes' competitive spirit could spill over into increased levels of drinking.

According to Watson (2002), coping with success and failure poses a formidable challenge to student-athletes and this may result in their poor choice of coping strategies (for example alcohol, substance use). It is also early in their university life that student-athletes have a higher misconception of alcohol consumption and engage in more sensationseeking behaviour than non-athletes (Anon, 2008). Younger student-athletes also tend to underestimate influence of alcohol on their workouts, endurance and mental frame of mind, hence they tend to show little concern regarding the quantity of alcohol they consume (Center for Student Health Promotion \& Well-being, 2014). As student-athletes gain more experience, grow older and become more mature, they are able to exercise more control over their alcohol consumption, which may enable them to cope better.

Some studies (Munro, 2000; Turner, 2008) point to the fact that alcohol and sport are united in close partnership and are best consumed simultaneously. This is evident in popular sports such as soccer and rugby where alcohol is consumed before, during and after a match. In fact, it would be unusual to view a sporting event without seeing some form of event signage or a commercial for an alcohol product (McDaniel, Kinney \& Chalip, 2001).

\section{Recommendations}

Given the fact that the consumption of alcohol will not suddenly disappear from the lives of student-athletes, it is essential to control it. Thus, arising from the findings of the study are a few recommendations. It is recommended that studentathletes should be educated in alcohol consumption from the time they start their practice sessions. This could be done through monthly counselling sessions for all athletes, regardless of whether they consume alcohol. Regular sessions will reinforce the idea that alcohol consumption could be detrimental to their athletic careers.

Sport psychologists should engage regularly with student athletes so that early warning signs regarding alcohol consumption are detected and addressed immediately. Furthermore, there should be support services in place to help athletes cope with stress.

\section{Conclusion}

It cannot be disputed that student-athletes engage in undesirable behaviours such as alcohol consumption and drug abuse. While alcohol, consumed in moderation, can prove harmless and potentially beneficial, it is of concern that alcohol consumption of student-athletes have become an acceptable part of their student life. Therefore, it is important that such practice is monitored closely, as it can have serious consequences on their athletic as well as academic careers.

\section{References}

Anon (2008). Drug issues with athletes. [Online] Available: http://myplaybook.drugfreesport.com/collegiate-program/drug-issues-withathletes/ (March 21, 2014).

Bernstein, N., Foxcroft, C., McCallum, W., Schultheiss, D., Seymour, B., \& Stead, G. (2007). X-kit undergraduate. statistics for social sciences. Cape Town: Maskew Miller, Longman.

Brenner, J., \& Swanik, K. (2007). High-risk drinking characteristics in collegiate athletes. Journal of American College Health, 56(3), 267272.

Cavenar, J. D., \& Werman, D. S. (1981). Origins of the fear of success. American Journal of Psychiatry, 138, 95-98.

Center for Student Health Promotion \& Well-being (2014). Alcohol and athletes. [Online] Available: http://oade.nd.edu/educate-yourselfalcohol/alcohol-and-athletes/ (March 21, 2014). .

Cohen, J. (1988). Statistical power analysis for the behavioral sciences (2nd ed.). New Jersey: Lawrence Erlbaum.

Creswell, J. W. (2014). Qualitative, quantitative, and mixed methods approaches. (4th ed.). Thousand Oaks, CA: Sage. 
Doumas, D., Turrisi, R., \& Wright, D. (2006). Risk factors for heavy drinking in college freshmen: Athletic status and adult attachment. The Sports Psychologist, 20, 419-434.

Sports, school, social life: Student athletes 'only have time for 2'. [Online] Available: http://www.kval.com/news/local/ Athleticsacademics-social-life-As-a-student-athlete-you-only-have-time-for-2-162295596.htmlSports, school, social life: Student athletes 'only have time for 2' (March 21, 2014).

Ford, J. A. (2007). Alcohol use among college students: A comparison of athletes and non-athletes. Substance Use \& Misuse, 42, 13671377.

Hingson, R., Heeren, T., Winter, M., \& Wechsler, H. (2005). Magnitude of alcoholic-related mortality and morbidity among US college students ages 18-24: Changes from 1998 to 2001. Annual Review of Public Health, 26, 259-279.

Holden, L. (2014). For student-athletes, 'striking a balance' between sports and academics often a struggle. [Online] Available: http://news.medill.northwestern.edu/chicago/news.aspx?id=229452 (March 21, 2014).

Hyatt, R. (2003). Barriers to persistence among African American intercollegiate athletes: A literature review of non-cognitive variables. College Student Journal, 37(2), 260-275.

Leichliter, J. S., Meilman, P. W., Presley, C. A., \& Cashin, J. R. (1998). Alcohol use and related consequences amongst students with varying levels of involvement in college athletics. Journal of American College Health, 46(6), 257-262.

Lorenzen, M., \& Lucas, N. (2003). Introducing first-year student-athletes to the library: The Michigan State University experience. [Online] Available: http://www.libraryinstruction.com/athlete.html (October 17, 2010).

Malhotra, N. K. (2007). Marketing research: An applied orientation (5th ed.). Upper Saddle River, NJ, USA: Pearson Prentice Hall.

McDaniel, S. R., Kinney, L., \& Chalip, L. (2001). A cross-cultural investigation of the ethical dimensions of alcohol and tobacco sports sponsorships. Teaching Business Ethics, 5(3), 307-321.

McDonald, S., \& Hardy, C. (1990). Affective response patterns of the injured athlete: An exploratory analysis. The Sport Psychologist, 4, 261-274.

Munro, G. (2000). Challenging the culture of sport and alcohol. International Journal of Drug Policy, 11, 199-202.

Nelson, T. F., \& Wechsler, H. (2001). Alcohol and college athletes. Medicine and Sciences in Sport and Exercise, 33(1), $43-47$.

Nelson, T. F., \& Wechsler, H. (2003). School spirits: Alcohol and collegiate sports fans. Addictive Behaviours, 28, 1-11.

Nunnally, J. C., \& Bernstein, I. H. (1994). Psychometric theory (3rd ed.). New York: McGraw-Hill.

Olivares, J. (2005). Student athletes face stress on and off the field. [Online] Available: http/l:www.media.lewisflyer.com/media/ storage/paper638 (June 05, 2009).

Parham, W. (1993). The intercollegiate athlete: A 1990's profile. The Counseling Psychologist, 21, 411-429.

Perkins, H. W. (2002). Social norms and the prevention of alcohol misuse in collegiate contexts. Journal of Studies on Alcohol, Supplement (14), 164-172.

Singh, P. C., \& Surujlal, J. (2006). Athlete satisfaction at universities in Gauteng. South African Journal for Research in Sport, Physical Education and Recreation, 28(2), 121-131.

Surujlal, J., Nolan, V. T., \& Ubane, T. (2012). Drinking patterns and related consequences among university student-athletes. African Journal for Physical, Health Education, Recreation and Dance, 18(2), 277-287.

The Higher Education Center for Alcohol and Other Drug Abuse and Violence Prevention (2008). College athletes and alcohol and other drug use. [Online] Available: http://www.higheredcenter.org/files/product/fact_sheet3.pdf (March 27, 2010).

Toporek, B. (2011). Student-athletes use less drugs, more alcohol than peers, study finds. [Online] Available: http://blogs.edweek.org/edweek/schooled_in_sports/2011/06/studentathletes_use_less_drugs_more_alcohol_than_peers_study_finds.html (March 21, 2014).

Turner, K. (2008). Alcohol and sport sponsorship: the effect of involvement and congruence on attitudes. [Online] Available: http://www.anzmac07.otago.ac.nz/anzmacCD/papers/KTurner (November 25, 2008).

Van Zyl, Y., Surujlal, J., \& Singh, C. (2009). An empirical study of university student-athletes' strategies for coping with stress. African Journal for Physical, Health Education, Recreation and Dance (Supplement), 62-78.

Watson, J. C. (2002). Assessing the potential for alcohol-related issues among college student-athletes. Athletic Insight: The Online Journal of Sport Psychology, 4(3), 14-27.

Wechsler, H., Davenport, A., Dowdall, G., Grossman, S., \& Zanakos, S. (1997). Binge drinking, tobacco, and illicit drug use and involvement in college athletics: A survey of students at 140 American colleges. Journal of American College Health, 45, 195200. 